\title{
Has the Luangwa (Zambia) hippopotamus (Hippopotamus amphibius) population stabilized after reaching its asymptote? What are the management challenges?
}

\author{
Chansa Chomba ${ }^{1^{*}}$, Twakundine Simpamba $^{2}$, Vincent Nyirenda $^{3}$ \\ ${ }^{1}$ Disaster Management Training Centre, Mulungushi University, Kabwe, Zambia; \\ *Corresponding Author: chansachomba@rocketmail.com, ritachansa@yahoo.com \\ ${ }^{2}$ Department of Research, Chinzombo Research Centre, Mfuwe, Zambia \\ ${ }^{3}$ Department of Research, Planning, Information and Veterinary Services, Chilanga, Zambia
}

Received 23 August 2013; revised 19 September 2013; accepted 27 September 2013

Copyright (C) 2013 Chansa Chomba et al. This is an open access article distributed under the Creative Commons Attribution License, which permits unrestricted use, distribution, and reproduction in any medium, provided the original work is properly cited.

\begin{abstract}
The population size of hippo (Hippopotamus amphibius Linnaeus 1758) in Luangwa valley, Zambia was earlier assessed for the period 19762008 and repeated 2009-2012 and found to have reached and maintained carrying capacity $K$ of 6000 individuals over a $165 \mathrm{~km}$ river stretch. This study covered the period 2009-2012 and used river bank count method as in previous studies. The method involved counting individuals and taking GPS locations of hippo schools. During the period 2009-2012 the population had maintained irregular cycles oscillating above and below $K$ of 6000 and was still within carrying capacity band of 2000 individuals. The highest population size was still 6832 hippos (rounded off to 7000) and density of $42 / \mathrm{km}$ reached in 1984 , and the lowest was 4765 hippos (rounded off to 5000 ) and density of $29 / \mathrm{km}$ recorded in 1978 . Between 1976-2008, and 2009-2012 the population still oscillated between 5000 - 7000 individuals, which is symptomatic of a population that had reached its asymptote. Plot of population size for the period 1976-2012 assumed a population model which was a hybrid between less accurate regulation and stable limit cycle. The slowdown in population growth at $K$ and oscillations were attributed to environmental resistance. More studies are required to identify the impact of climate change on the population size and density fluctuations to determine whether $K$ will rise or drop.
\end{abstract}

Keywords: Hippo; Density; Population; Stability; Asymptote; Carrying Capacity; Oscillations

\section{INTRODUCTION}

Common hippopotamus commonly called hippo (Hippopotamus amphibius Linnaeus 1758) population along $165 \mathrm{~km}$ stretch of the Luangwa River has been studied since the 1800s. In 1976, a stretch of $165 \mathrm{~km}$ was demarcated for intensive monitoring using the same survey methods. Results of this monitoring showed that the population recorded high densities of up to $42 \mathrm{hippos} / \mathrm{km}$ during the period 1976-2008 [1]. It exceeded and dropped below 6000 individuals in seven irregular cycles. Culling and anthrax such as the outbreak of 1987-1988 seasons reduced the population below 5000 individuals, but the population rose again to surpass 6000 by 1989 . Since the ecological carrying capacity $(K)$ and carrying capacity band had not been determined [2,3], they were estimated to be 6000 and 2000 individuals respectively.

Knowing the ecological carrying capacity and carrying capacity band were found to be necessary as a tool in adaptive management, as these would also help Zambia Wildlife Authority (ZAWA) set sustainable trophy hunting quotas and other off takes and to effectively manage the range in a manner which takes into account the needs of other herbivores using the same range.

\section{Carrying Capacity}

In estimating carrying capacity for the Luangwa hippo [3], it was assumed that the concept of carrying capacity was still undergoing scientific debate amongst population 
ecologists regarding its use. However, in the 1976-2008 study as well as this study (2009-2012) it was assumed that since hippo is a grazer whose population growth is often regulated by food supply, the concept of carrying capacity was still valid and was used in order to determine the amount of biomass required to sustain a given population size above which the population would experience food shortage and decline in response to limited food supply and vice versa.

It was also acknowledged that studies conducted on hippopotamus population dynamics are few relative to other species of similar size, but based on the limited studies carried out, it was expected that the Luangwa hippopotamus population would grow and then fluctuate about an equilibrium level and then stabilize. This was expected, because, in principle, when there are too many individuals in a population, individuals get depressed by lack of resources, social conflicts, predation or disease. Secondly, since food production varies from year to year depending on amount of rainfall, herbivores follow a similar pattern [4]. When the animal numbers are low there would be excess resources, so the population increases unless predators hold them down [5]. The assumption was based on a simple and general description of population growth given in the logistic curve (Figure 1), where line $K$ shows population size at carrying capacity of the area which is the maximum number of animals an area can support in terms of food supply, places to live and many other habitat welfare factors. At very low density population growth is greatest, but as the size approaches $K$, the rate of increase declines progressively until $K$. Based on this view [4], which contrasted with that of Zambia Wildlife Authority (ZAWA), food was suggested to be the main factor regulating Luangwa hippo population and not security against poaching. This view contrasted with that of ZAWA where security and mortality were considered to be the main factors regulating the Luangwa hippo population.

Based on the illustration provided in Figure 1 and the concept of population dynamics, it was evident that carrying capacity, $K$, was not constant but a factor often modified by climate, number of other herbivores using the same habitat and many others usually summed up as environmental resistance. Carrying capacity therefore, was taken to be an equilibrium point at which the rate of production of edible forage equaled the rate at which the forage was consumed by animals [6]. This equilibrium point was also referred to as the saturation density or ecological carrying capacity [7-10].

In reality therefore, there cannot be a single carrying capacity; instead there is a band, the carrying capacity band within which animal population fluctuates (or is regulated) depending on overall resources' availability in

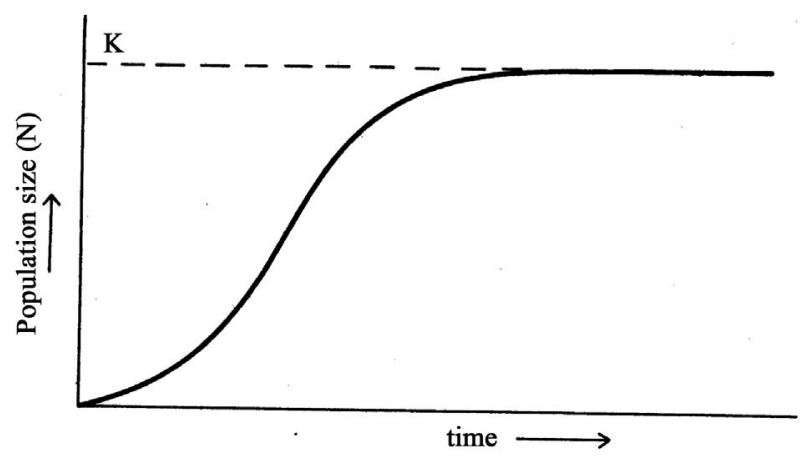

Figure 1. The logistic curve, $K$ is the population size at ecological carrying capacity of the area (Chapman and Reiss, 2000).

the environment [5]. Four main scenarios of population regulation have been suggested as shown in Figure 2 which was later amplified [4]. Based on this model it was assumed that if food was the main factor regulating the Luangwa hippopotamus population, a plot of population size and density overtime would produce a graph similar to one of the four models in Figure 2 [5]. In the studies 1976-2008 for instance, food was found to be the main factor responsible for the hippo population regulation.

Recommendations were made at the conclusion of the 1976-2008 study [4] to determine factors regulating the rise and fall, and which model the hippo population would follow after reaching the asymptote. Such information was found to be invaluable for effective management of the hippo population and its habitat $[3,4,11]$. Empirical evidence derived from such research would ensure that management decisions regarding consumptive utilization of the population are sustainable.

In this study, 2009-2012 we assessed the population size and density to determine whether the population had maintained the same carrying capacity of 6000 individuals and remained within the carrying capacity band of 2000 individuals and the population model it had assumed [4].

\section{METHODS AND MATERIALS}

\subsection{Study Area}

\section{Location of Study Area}

The study was conducted in the Luangwa River and valley in eastern Zambia (Figure 3). It covered the river length for $165 \mathrm{~km}$, starting from the Chibembe pontoon $\left(12^{\circ} 48^{\prime} \mathrm{S}, 32^{\circ} 03^{\prime} \mathrm{E}\right)$ to the Lusangazi-Luangwa confluence $\left(13^{\circ} 24^{\prime} \mathrm{S}, 31^{\circ} 33^{\prime} \mathrm{E}\right)$ as earlier described [2], and provided under Table 1.

This subdivision was adopted in 1976 based on administrative arrangements and management of field logistics such as delivery of supplies to the study crew and 

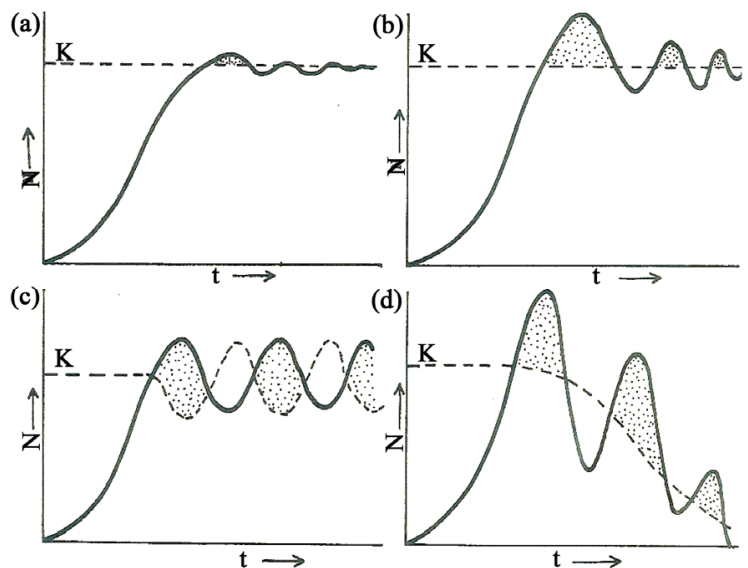

Figure 2. Models of population regulation: (a) Shows almost perfect regulation to the equilibrium level with only minor fluctuations about $k$; (b) Shows less accurate regulation at first but gradually the equilibrium level is reached and then maintained; (c) Shows that perfect regulation is never achieved; instead the population shows a constant cycle of change, oscillating with $k$ in a regular way. (This is called a stable limit cycle); and (d) Shows an extreme case of failure to regulate; the population overshoots $k$ so much that $k$ itself is reduced and eventually the population plunges itself to extinction, (Sinclair and Grimsdell, 1982).

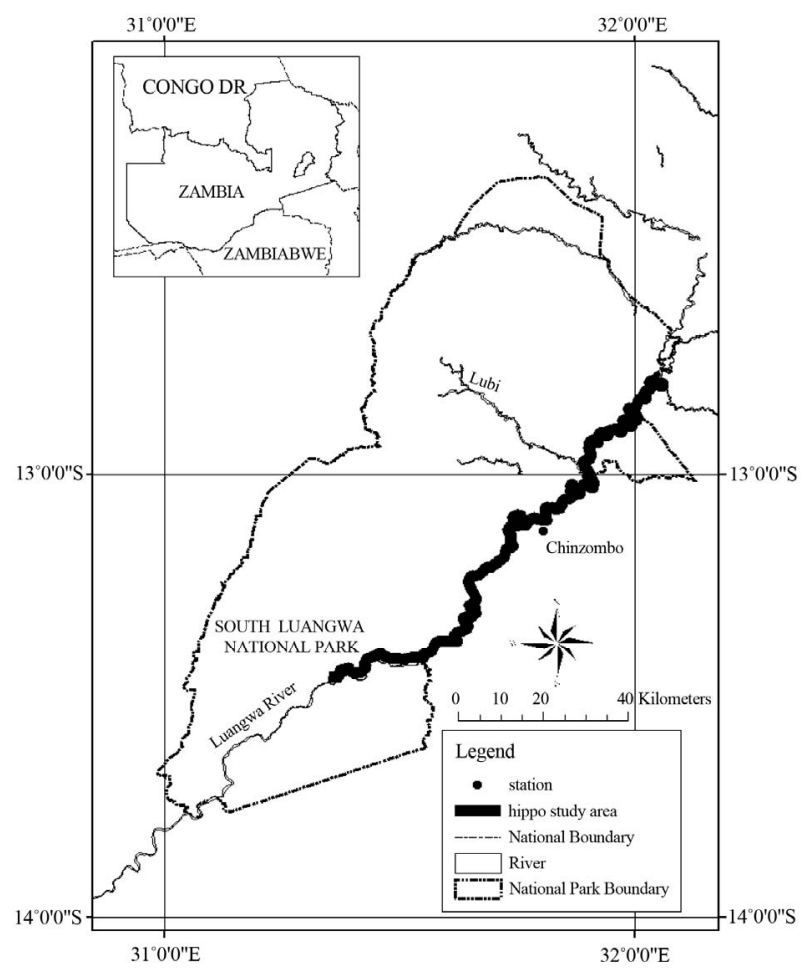

Figure 3. Location of study area along Luangwa River and South Luangwa National Park in Zambia. The study area is divided into study blocks A to H (Table 2).

shelter for sleeping during hippopotamus counts. Administratively, the upper and lower blocks also belong to different management sectors. The upper blocks (A-D)
Table 1. Details of the study area blocks along the $165 \mathrm{~km}$ stretch of the Luangwa River, Zambia.

\begin{tabular}{|c|c|c|}
\hline Study block & GPS coordinates & Distance \\
\hline \multicolumn{3}{|c|}{ Upper study blocks } \\
\hline A & E $12^{\circ} 46^{\prime} 42^{\prime \prime} ;$ S $032^{\circ} 02^{\prime} 55^{\prime \prime}$ & $16.1 \mathrm{~km}$ \\
\hline B & E $12^{\circ} 50^{\prime} 48^{\prime \prime} ;$ S $032^{\circ} 00^{\prime} 09^{\prime \prime}$ & $45.3 \mathrm{~km}$ \\
\hline $\mathrm{C}$ & E $12^{\circ} 59^{\prime} 40^{\prime \prime} ;$ S $031^{\circ} 54^{\prime} 14^{\prime \prime}$ & $14.2 \mathrm{~km}$ \\
\hline $\mathrm{D}$ & E $13^{\circ} 03^{\prime} 14^{\prime \prime} ;$ S $031^{\circ} 52^{\prime} 29^{\prime \prime}$ & $15.6 \mathrm{~km}$ \\
\hline \multicolumn{3}{|c|}{ Lower study blocks } \\
\hline $\mathrm{E}$ & E $13^{\circ} 05^{\prime} 53^{\prime \prime} ;$ S $031^{\circ} 47^{\prime} 10^{\prime \prime}$ & $20.2 \mathrm{~km}$ \\
\hline $\mathrm{F}$ & E $13^{\circ} 05^{\prime} 45^{\prime \prime} ;$ S $031^{\circ} 44^{\prime} 09^{\prime \prime}$ & $16.4 \mathrm{~km}$ \\
\hline G & E $13^{\circ} 14^{\prime} 39^{\prime \prime} ;$ S $031^{\circ} 38^{\prime} 54^{\prime \prime}$ & $24.6 \mathrm{~km}$ \\
\hline $\mathrm{H}$ & E $13^{\circ} 22^{\prime} 35^{\prime \prime} ;$ S $031^{\circ} 36^{\prime} 41^{\prime \prime}$ & $12.6 \mathrm{~km}$ \\
\hline Total & & 165 \\
\hline
\end{tabular}

belonged to Nsefu sector and the lower ones (E-H) to Lusangazi sector of the South Luangwa National Park. The total area covered by this study was $660 \mathrm{~km}^{2}$.

\subsection{Field Methods}

\section{i) Total Counts along the Luangwa River}

In this study 2009-2012, river bank total count method was used as earlier described [2,4], where six members of the research team walked along the bank of the river. Of the six, two were recorders one recording on data sheets and the other on the map. Two were observers using a pair of binoculars each and the other two carried firearms to protect the team from dangerous animals such as elephant, lion, crocodile and hippo (Figure 4). Up to 30 minutes were spent observing a spotted hippo school, which provided sufficient time to count and classify individuals into age groups and sex based on body size and where visible external genitalia. The size of each school was recorded and GPS coordinates taken. Data for the period 1976-2008 were also accessed from earlier studies [4]. Such data were used to compare with results of the 2009-2012 survey and to determine whether the population size, density and carrying capacity band had changed since 2008 when the last analysis was conducted [4].

ii) Calculating Population's Mean Size and Density

To compare population's mean size and density, a summary table of population size and density obtained during the period 2009-2012 was compared with the 1976-2008 data. The total figure of population size recorded each year from 2009-2012 were added up and divided by the total number of years to obtain mean po- 


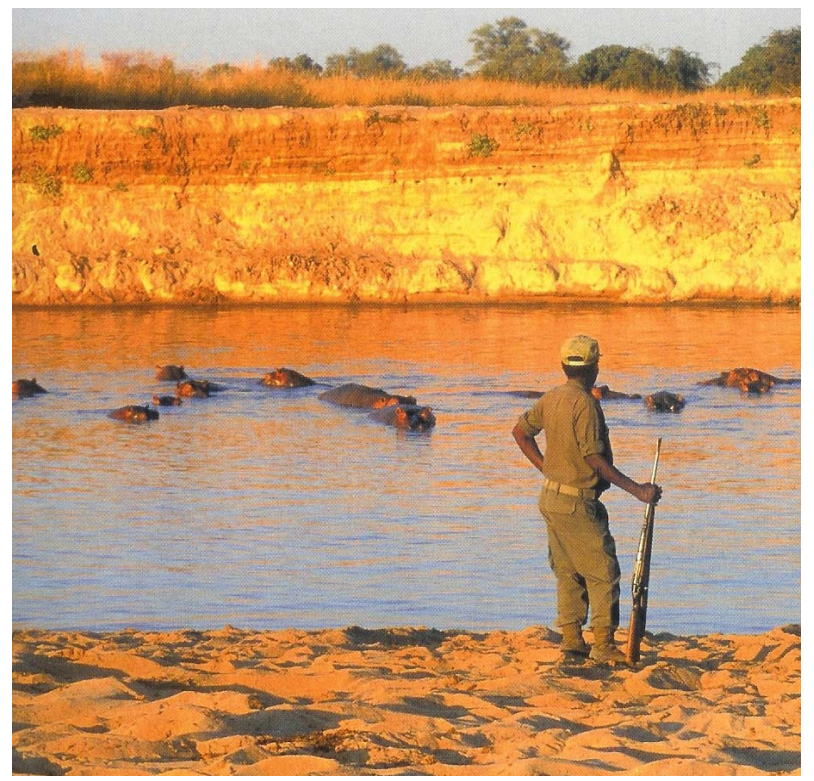

Figure 4. Wildlife Police Officer with a fire arm protecting research team during river bank total count method for the hippopotamus along the Luangwa River, Zambia.

pulation size for the period 2009-2012 using MS Excel computer software programme based on the formula used in earlier studies [12]:

$$
\bar{X}=\frac{\sum x}{N}
$$

Hippopotamus density was also calculated by dividing river length of $165 \mathrm{~km}$ by population size based on the formula:

$$
D=\frac{N}{L}
$$

where; $D$ is density; $N$ is the number of hippopotami and $L$ is the river length.

Population size data for the period 2009-2012 were entered in MS Excel programme and then imported into Minitab Release 14 Statistical Software programme. These data were then added to have hippopotamus population profile for the period 1976-2012 (36 years). A horizontal line representing population mean for the period 19762012 was automatically generated from the $Y$ axis of the chart to the point of the curve where the population leveled off.

\section{RESULTS}

\section{Population Status and Carrying Capacity}

The mean hippopotamus population size, density/km and carrying capacity band for the $165 \mathrm{~km}$ river stretch of the river for the period 1976-2012 was 6000 individuals at $K$, while $35 / \mathrm{km}$ was mean density and 2000 individuals as carrying capacity band. These results were the same as those obtained during the period 1976-2008 (Figure 5 and Table 2). The point of stability in the

Table 2. Hippopotamus population size and density rise and

\begin{tabular}{|c|c|c|c|c|}
\hline Year & $\begin{array}{l}\text { Population } \\
\text { size }\end{array}$ & $\begin{array}{l}\text { Annual } \\
\text { change }\end{array}$ & $\begin{array}{c}\text { Density } \\
\text { below } K \\
(35 / \mathrm{km})\end{array}$ & $\begin{array}{l}\text { Density } \\
\text { above } K \\
(35 / \mathrm{km})\end{array}$ \\
\hline 1976 & 4919 & 646 & 30 & \\
\hline 1977 & 5147 & -382 & 31 & \\
\hline 1978 & 4765 & 386 & 29 & \\
\hline 1979 & 5151 & -267 & 31 & \\
\hline 1981 & 4884 & 1409 & 30 & \\
\hline 1982 & 6293 & 251 & & 38 \\
\hline 1983 & 6544 & 288 & & 39 \\
\hline 1984 & 6832 & -252 & & 42 \\
\hline 1985 & 6580 & 161 & & 40 \\
\hline 1986 & 6741 & -1219 & & 40 \\
\hline 1987 & 5522 & -233 & 33 & \\
\hline 1988 & 5289 & 1032 & 32 & \\
\hline 1989 & 6321 & 174 & & 38 \\
\hline 1990 & 6495 & -844 & & 39 \\
\hline 1991 & 5651 & -151 & 34 & \\
\hline 1992 & 5500 & -147 & 33 & \\
\hline 1993 & 5353 & 1096 & 32 & \\
\hline 1994 & 6449 & -563 & & 39 \\
\hline 1995 & 5886 & -360 & & 36 \\
\hline 1996 & 5226 & -196 & 33 & \\
\hline 1997 & 5330 & -426 & 32 & \\
\hline 1998 & 4904 & 285 & 30 & \\
\hline 1999 & 5189 & 749 & 31 & \\
\hline 2000 & 5938 & 231 & & 36 \\
\hline 2001 & 6169 & 103 & & 37 \\
\hline 2002 & 6272 & 78 & & 38 \\
\hline 2004 & 6350 & -220 & & 38 \\
\hline 2005 & 6130 & 239 & & 37 \\
\hline 2006 & 6369 & -51 & & 38 \\
\hline 2008 & 6318 & -38 & & 38 \\
\hline 2009 & 6331 & 13 & & 38 \\
\hline 2010 & 6150 & -81 & & 37 \\
\hline 2011 & 6738 & 588 & & 41 \\
\hline 2012 & 6777 & 39 & & 41 \\
\hline Range & & & $2-5$ & $2-11$ \\
\hline Mean & 6000 & & $4(3.5)$ & $7(6.5)$ \\
\hline Mean decrease $(-v e)$ & & -339 & & \\
\hline Mean increase $(+v e)$ & & 432 & & \\
\hline
\end{tabular}
fall around $K$, Luangwa River, Zambia.

Notes: Density at $K$ was $35 / \mathrm{km}$. 


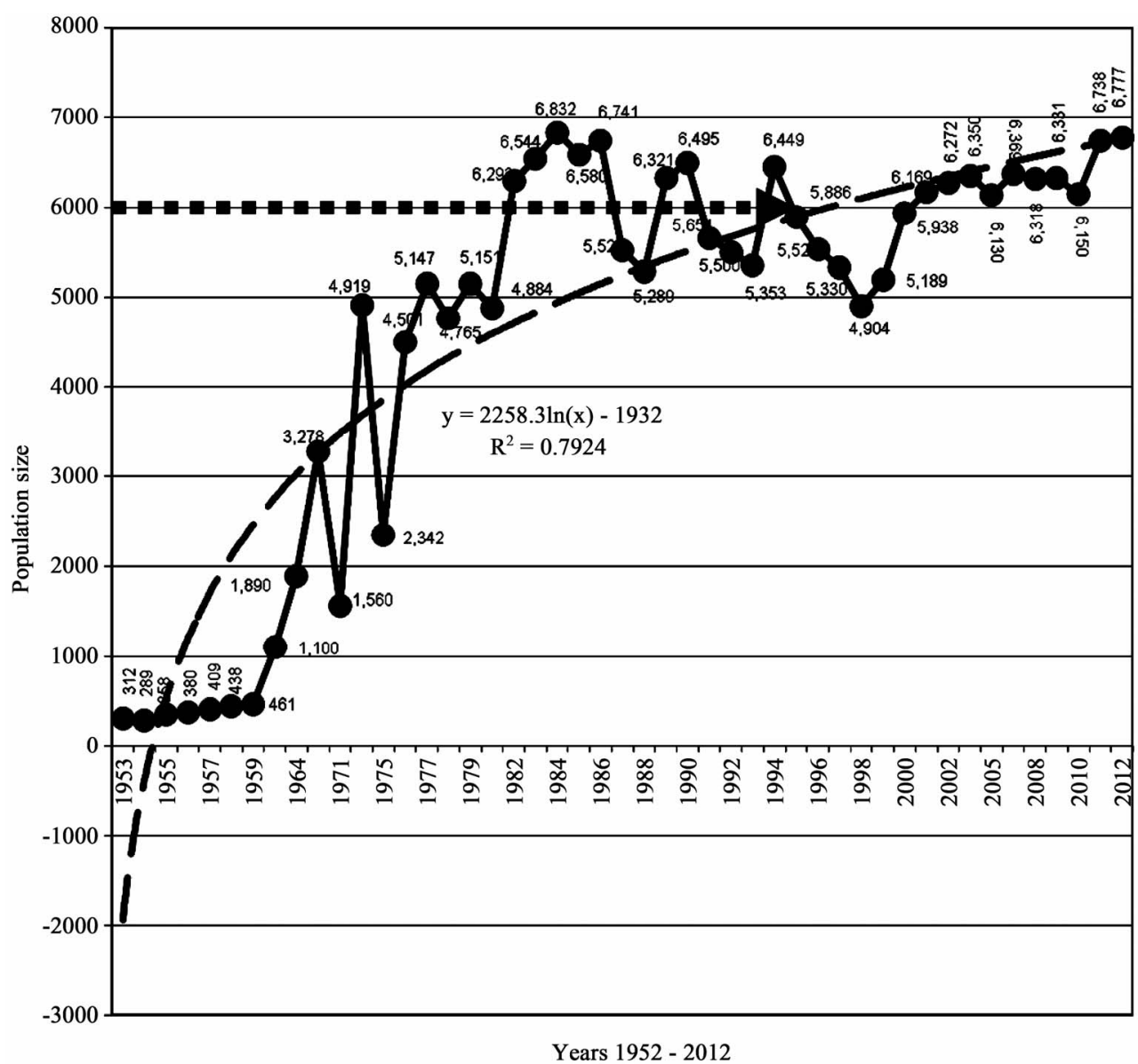

(a)

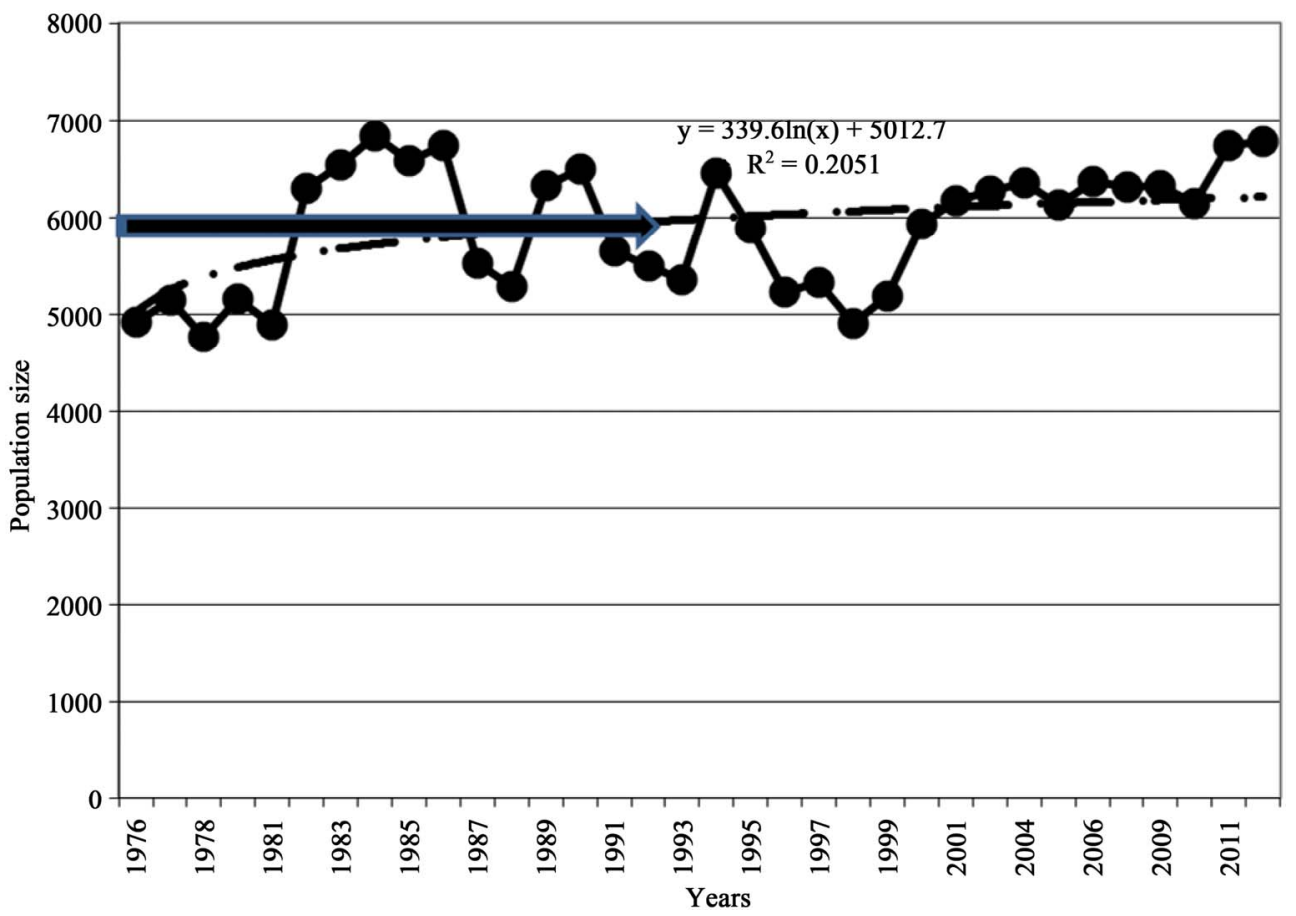

(b)

Figure 5. Population performances (a) 1952-2012 and (b) 1976-2012, Luangwa River, Zambia. 
population growth curve was still 6000 individuals and this was taken to be $K$ (Figures 5(a) and (b)).

From this point of stability $K$, annual population changes for both population size and density were small and insignificant $(\mathrm{P}>0.05)$. The correlation coefficient $\mathrm{R}^{2}=0.205$ still showed a weak positive correlation between population size as dependent variable and time as independent variable $(\mathrm{y}=339.6 \mathrm{Ln}(\mathrm{x})+5012)$ (Figure 5(b)) and was similar to the figures obtained during the period 1976-2008 which were $\mathrm{R}^{2}=0.191(\mathrm{y}=314.73 \operatorname{Ln}(\mathrm{n})$ +4998 ), suggesting a slow and insignificant population growth, which is characteristic of a population at $K$.

\section{i) Carrying Capacity Band}

The carrying capacity band for the period 1976-2012 was still 2000 individuals, as was the case for the period 1976-2008. The highest population size reached for the period 1976-2012 was still 6832 (rounded off to 7000) and density of $42 / \mathrm{km}$ in 1984; the lowest was also 4765 (rounded off to 5000) and density of $29 / \mathrm{km}$ in 1978 (Figure 6). These figures have not changed, which is also a confirmation that the population had stabilized at K.

These results show that carrying capacity band which was the difference between the highest value of 7000 and lowest value of 5000 remained the same (Figure 6). The population remained within the same range of 5000 (lower limit) - 7000 (upper limit) in the last 36 years 1976-2012 signifying a hybrid stability model combining graphs "c" and "b" of Figure 2 which is characteristic of a population at $K$.

ii) Population Oscillations within Carrying Capacity Band

The population size and density fluctuated between 5000 (density 29/km) and 7000 individuals (density $42 / \mathrm{km}$ ) respectively, in 9 irregular cycles of 5 times below $K$, with each cycle lasting 4 years (mean of 3.5, rounded off to 4years), and 4 times above $K$ with each cycle lasting 7 years (mean of 6.5 , rounded off to 7 years), (Figure 6 and Table 2). Frequencies observed were the actual number of years the population spent above or below $K$ and the frequency expected was the mean value obtained by dividing the total number of years by the number of cycles. The differences in the number of years when the population was above and below $K$ varied significantly $(\mathrm{P}<0.05)$ (Table 2$)$ implying that cycles were irregular. If the cycles were regular, the population could have maintained the same number of years below and above $K$. However, density changes for the period 19762012 were insignificant $(\mathrm{P}>0.05)$ (Figure 7).

If cycles were regular the population was expected to take 5.5 years above $K$ and 5.5 years below $K$. Instead, it took more years above $K$ ( 7 years) and fewer years be

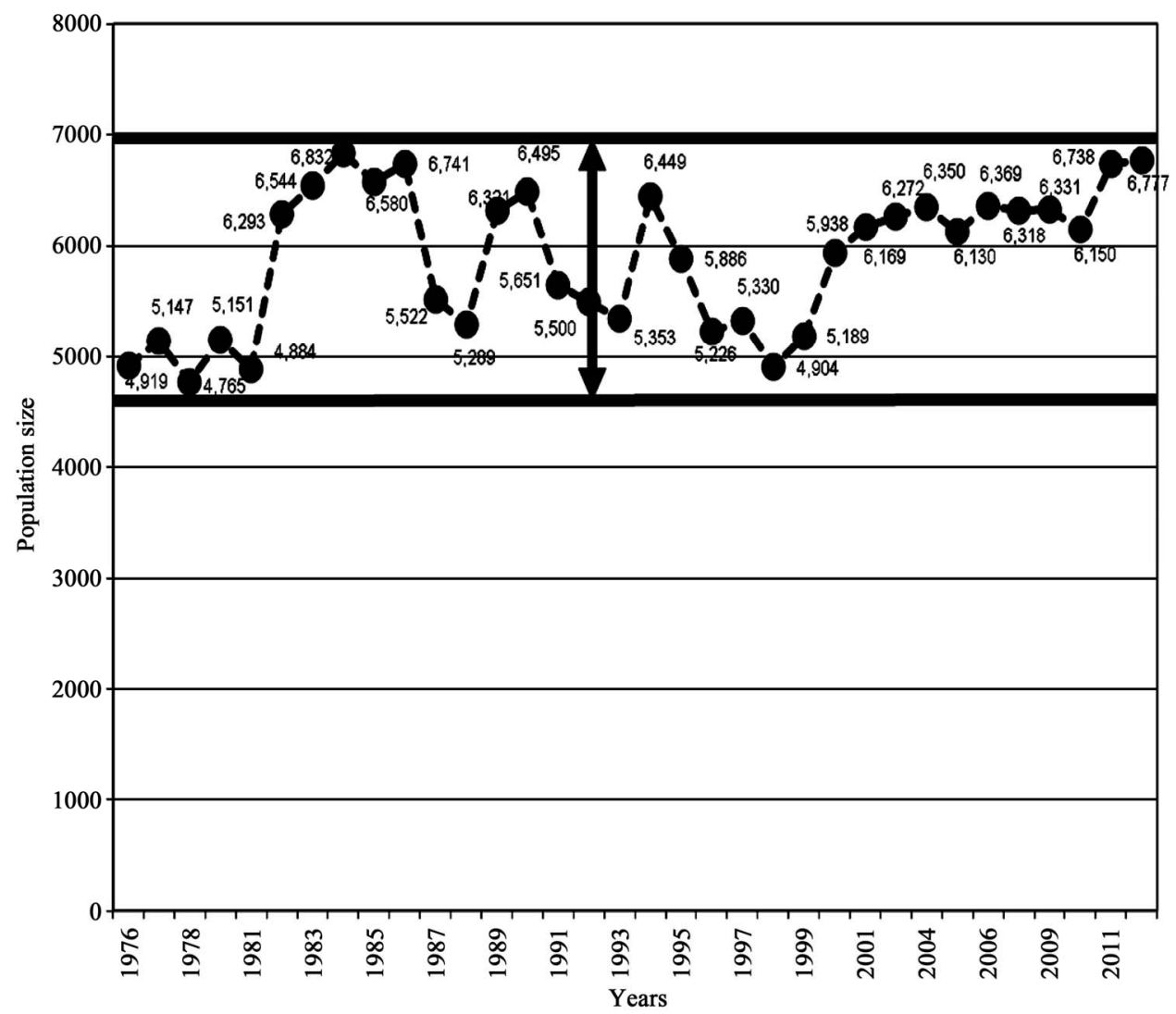

Figure 6. Carrying capacity band for the Luangwa Hippopotamus population, 1976-2012, Zambia. 


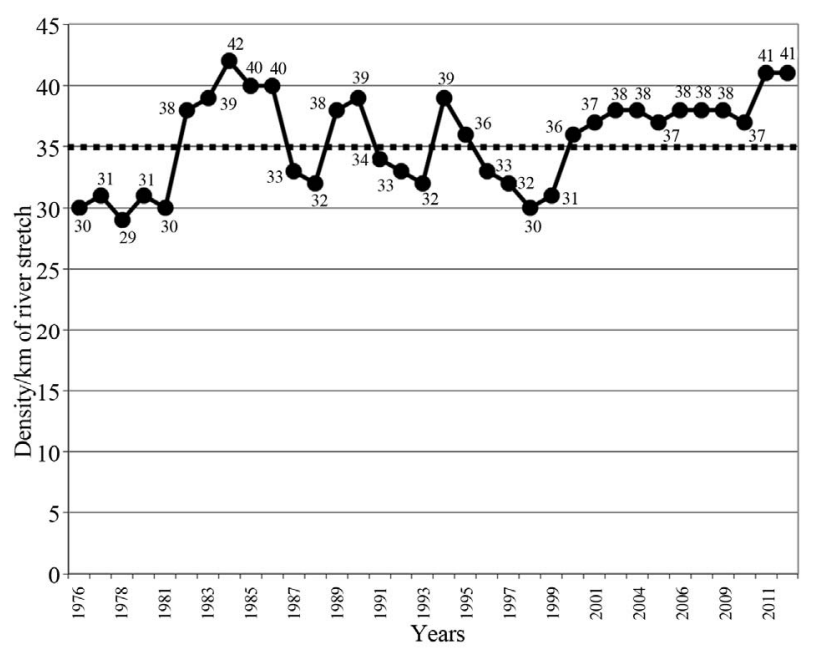

Figure 7. Hippopotamus population density for the period 1976-2012, Luangwa River, Zambia.

low $K$ (4 years) giving an irregular pattern of oscillations. There variations were statistically significant $(\mathrm{P}<0.05)$.

The irregular pattern of rise and fall in population size was also related to annual change in population size. It increased in some years and declined in others as shown in column 3 of Table 2 and such changes varied significantly from year to year $(\mathrm{P}<0.05)$, with the largest increase being 1409 in 1981 and largest decrease of -1219 in 1986 (Table 2), suggesting oscillations in population size between years, which has remained the same since the last survey (1976-2008).

\section{DISCUSSION}

\subsection{Population Status of the Luangwa Hippopotamus}

The Luangwa hippopotamus population size along the $165 \mathrm{~km}$ stretch reached ecological carrying capacity, $K$ at 6000 individuals and has been oscillating within the carrying capacity band of 2000 individuals since 1976. Population stability $K$ was achieved after a period of more than 100 years from the late 1890 s when the population was almost decimated [1-4] to the current decade. From the 1950s the population increased to hundreds until the mid 1960s. Between 1952 and 1960 there was slow growth followed by a period of rapid or exponential growth to 1976. Subsequently, food resources and habitat welfare factors such as; territories, basking and wallowing areas became limiting. Such limitations gradually reduced birth and survival rates of the population. As births and survival rates slowed down, the population leveled off and started to fluctuate. This has not changed since 2008 [4]. The summation of direct environmental factors such as mortality and food availability and indirect factors such as climate, fire, habitat changes and natural catastrophes collectively formed environmental resistance which ultimately determined the number at which the population would stabilize. Environmental factors coupled with social behaviour of hippos, prevented further growth of the population above 7000 individuals and caused fluctuations in population size and density. Studies carried out in South Africa [13] showed that every animal species tolerates a certain degree of density after which social behavioural factors prevent further crowding irrespective of whether there is sufficient food or not. Furthermore, since the environmental factors are not constant, they fluctuate from year to year; populations also follows the same pattern.

It is now assumed that the leveling off of the Luangwa hippopotamus population was caused by environmental resistance while the annual variations in environmental factors caused the population to fluctuate as births and deaths tended to balance each other. The balance between deaths and births was not perfect as the amount of food was varying from year to year as influenced by the amount and spatial distribution of rainfall [2-4].

The rise of population in good years and decline during bad years (Table 2) caused oscillations around $K$, with a vertical amplitude of 2000 individuals. As depicted in Figure 6 the hippopotamus population size could not stabilize to form a straight line at $K$ because the amount of food (grass biomass) produced and the available space for basking, wallowing, establishment of territories and other habitat welfare factors together regulated population size by influencing birth rates [4]. The hippopotamus population stability at $K$ therefore, assumed a hybrid form between graphs " $c$ " and " $b$ " of the population model shown in Figure 2.

These results conform to the examples provided in other studies [14] on how food regulates population size. These examples included lemming (Lemus), fox (Alopex and Vulpes), Canadian lynx (Lynx canadensis) mice (Muridae), snowshoe hare (Lepus americanus) and muskrat (Ondatra zibethica). The lemming population for example, increased rapidly from only one to two lemmings per hectare to about 30 or 40 lemmings per hectare. This increase occurred in only a few months [14]. Shortly afterwards, the numbers declined to earlier low levels and remained low for few subsequent years. The lemmings on the other hand, followed a four-year cycle. This pattern did not only occur in lemmings but also in mice (Muridae) and foxes [14]. Other species such as the snowshoe hare, muskrat and some foxes and the Canadian lynx had ten-year population cycles. It was then concluded that the rise and fall in these mammal populations was probably due to some favourable factor, which resulted in an increase in birth rates in some years and decrease in others [14]. The equally rapid fall in the population in the lemmings seemed to have resulted from a high death rate and lowering of birth rate due to envi- 
ronmental resistance. The population crash of these populations did not seem to be due to disease [14]. It was finally established that food and other welfare factors were responsible for the rise and fall of those populations.

Although data on hippopotamus population oscillations is limited, statistics from other mammals such as the Serengeti wildebeest [15], reindeer [16-18] and the ones recorded earlier [14], showed that food is the main factor regulating mammalian populations around $K$. It has now been established that population oscillations recorded during the present study about the Luangwa hippopotamus population size, was in response to fluctuations in food supply which lowered natality and not disease and other forms of mortality as previously thought. Food availability kept the population between 5000 - 7000 hippopotami in the last 36 years (19762012). The hippopotamus population could not exceed 7000 individuals due to environmental resistance particularly shortage of food, while the limitation of wallowing sites, basking areas and other habitat welfare factors also played a complementary role.

Even though population oscillations are common in many species of mammals and is well documented in the Serengeti wildebeest [15], it was however, recorded for the first time in common hippopotamus population during the present study. One may suspect that the factors causing the Luangwa hippopotamus population oscillations may not be similar to the factors responsible for the Serengeti wildebeest for the reason that the two populations live in different ecological settings and display different patterns of feeding behaviour. For instance, the Luangwa hippopotamus is resident in an ecological setting with unimodal rainfall regime and does not migrate, while the Serengeti wildebeest migrates in response to a bimodal rainfall regime. Notwithstanding the variation in ecosystems where the Luangwa hippopotamus and the Serengeti wildebeest are found, the role that food plays in regulating mammal population's growth rate is similar [13]. There is no doubt that the findings on the impact of food availability on Serengeti wildebeest also apply to the Luangwa hippopotamus population.

The carrying capacity of 6000 individuals which was maintained as confirmed by this study, was the equilibrium point at which growth stabilized and started to fluctuate in response to food availability which was also influenced by rainfall [4]. As earlier described [10] and as confirmed by this study, ecological carrying capacity is a point at which the rate of production of edible forage equals the rate at which the forage is consumed by animals. This equilibrium point was also termed as the saturation density or ecological carrying capacity [7-9]. At $K$ the animals are not necessarily in very good condition and their death rate equals their birth rate and re- cruitment rate is low and so the populations tends to stabilize. Reduced birth rates recorded in Luangwa hippopotamus population [4], subsequently caused reduction in population size, but as the population declined, more and more resources were freed and births increased again (Table 2). Such increases and decreases caused fluctuations in hippopotamus population size and density $/ \mathrm{km}$. Population increases represented years of high quality forage ("fat years") and decreases were years of low grass biomass ("lean years") (Figure 6), being largely determined by rainfall which was also identified as causal factor in the food production (grass biomass) for the Serengeti wildebeest [15].

Other than food production, hippos were also affected by annual rainfall variability due to their affinity for water. Because hippos spend most of day time in water or next to it; they exhibit notable demographic sensitivity to rainfall [19]. Field records and research conducted over the past 50 years in many parts of Africa including the Luangwa Valley have quantified marked changes in hippopotamus demographic rates in response to rainfall fluctuations [20-22]. In low rainfall or drought years, hippo populations can crash, because of a dramatic decline in conception and an abrupt increase in mortality, most likely due to shortage of forage, heat stress and increased vulnerability to disease such as anthrax [1-4, $22,23]$. The proportion of females likely to conceive in a drought year has been estimated to drop from $30 \%$ to $<5 \%$ [22]. Historical accounts from as early as 1929 from protected areas in South Africa, Tanzania, Zambia and Zimbabwe provide support for this pronounced response to low rainfall conditions [24]. Conversely, in response to higher than average rainfall, common hippopotamus population exhibit dramatic population surges [24]. During these surges, the population can return to pre-drought levels often in 1 to 2 years, because of high forage availability and increased reproductive activity from sexually mature adults. In high rainfall years, individuals younger than average age of sexual maturity may become sexually active in response to favourable conditions and contribute to population growth $[22,23]$.

In the present study, direct influence of rainfall on hippopotamus population could not be established. However, since it has been well documented that influence of rainfall on hippopotamus and other large mammal populations is through primary production which also impacts on animal population size $[9,10]$, there is no doubt that rainfall fluctuations in the Luangwa Valley contributed to the hippopotamus population fluctuations through food production.

Based on the description of carrying capacity provided by Mentis and Duke [5-9,25,26], it was implicit that the Luangwa hippopotamus population had maintained carrying capacity " $\mathrm{K}$ " and oscillations within Carrying $\mathrm{Ca}$ - 
pacity Band, over the last 36 years (1976-2012). The main factor keeping the population within the carrying capacity band over the last thirty-six years was primary production $[2,4]$. Other factors were places to live including places to establish territories, wallowing, cooling, and other habitat welfare factors. As the population increased, habitat welfare factors became limiting, coupled with food shortage, the animals could not derive optimum food requirements for good body condition and reproduction.

\subsection{Conclusions}

Results of the present study suggest that:

- Common hippopotamus population in the Luangwa River maintained carrying capacity of 6000 individuals and remained within the Carrying Capacity Band of 2000 individuals in the last thirty-six years (19762012); and

- Environmental resistance kept the population within carrying capacity band of 2000 individuals.

It was further established that the main factor responsible for the oscillations was food availability as influenced by rainfall. The lower limit which would hold 5000 hippopotami were "lean years" and upper limit which would hold 7000 hippopotami represented "fat years" and midpoint (6000) was $K$ for average years (Figures 5(a) and (b)). The difference between lower and upper limits was 2000 hippopotami representing Carrying Capacity Band in the last 36 years (19762012).

\subsection{Recommendations}

\section{a) Data Collection}

Previous studies on hippopotamus in the Luangwa Valley have been biased towards estimating population size. Results from the present study show that hippo population has been oscillating within a Carrying $\mathrm{Ca}$ pacity Band of 2000 hippos since 1976. The factors responsible have been identified as amount, spatial and temporal distribution of food along the $165 \mathrm{~km}$ stretch. Effective management of the Luangwa hippo therefore, will depend on effective management of pasture and monitoring amount and spatial distribution of rainfall which influences primary production.

We suggest the following areas of study:

\section{i) Establishment of a Common Format for Data Collection and Storage}

Currently field data is not stored in a systematic manner. A common format for data collection, storage and retrieval should be developed and maintained. Data stored in such a format would be easily retrieved and used in decision making and adaptive management strategies.

\section{ii) Consistent and Regular Counting}

Population counts of hippos and other large herbivores have not been consistent. Counting of hippo and other large herbivores should continue using similar methods in the established study blocks. In view of the impact of hippo as a dominant grazer on the pasture, Zambia Wildlife Authority should set Thresholds of Potential Change (TPC) and monitor hippo numbers and the habitat, such that when TPC are exceeded, animal numbers would be reduced and habitat monitored to ensure that it recovers. A no action stance on the hippo population size would likely amplify habitat transformation or may lead to a population crash. If the hippo population declined to very low levels, recovery may be slow or impossible since human encroachment is also taking away part of the hippo habitat particularly in areas where the National Park shares boundary with Game Management Areas. This assertion of slow population recovery if the hippo population declined to very low levels was based on the fact that the Luangwa hippo population took more than 100 years to reach the current carrying capacity of 6000 individuals. In the present study, it has been reported that the hippo population in the Luangwa Valley was in their thousands before the mid 1800s but was almost exterminated by the end of the 1800 s such that it was still at low ebb in the $1930 \mathrm{~s}$. It then increased rapidly to the $1980 \mathrm{~s}$ when numbers stabilized around 6000 along the $165 \mathrm{~km}$ stretch. At that time (1890-1976), the population managed to recover because the main limiting factor was poaching and not the habitat or food availability as there were few human settlements and virtually no agricultural activities along the Luangwa River. When poaching was minimized after the area was established as a National Park, the population grew rapidly to equilibrium point in the late 1970s to early 1980s. Currently, the landscape has changed, human settlements are increasing and agricultural activities are also expanding in areas that were previously left for wildlife management alone. If hippo population dropped to low levels ( $<1000$ individuals) as was the case before the 1960s, recovery under such circumstances would be a challenge as people are likely to encroach more and more on the hippo habitat. Once human settlements get established in the former range, it would not be politically feasible to later evacuate people for the sake of reclaiming hippo habitat. If on the other hand the consequences of global climatic change enhance dryness as opposed to wetness, hippopotamus habitat would also be reduced. This is a potential management problem that requires scientific investigation or the population's carrying capacity may decline.

\section{iii) Monitoring Hippopotamus Body Condition}

State of body condition clearly show signs of environmental stress through loss of body condition in the dry season. Zambia Wildlife Authority should therefore, 
initiate and maintain a comprehensive monitoring of hippo body condition using the same or better methods when available. Kidney Fat Index (KFI) method for instance, can be used as kidneys would easily be obtained from culled specimens and when culling ceases, from trophy hunting and control. This would ensure that management maintains a healthy hippo population capable of resisting environmental stresses such as disease.

\section{iv) Data Collection}

During the present study, it was found that collection of rainfall data at Chinzombo research station only resumed in 1999 after a period of more than 15 years when no rainfall data were collected. We highlight the need for management to collect data on basic environmental parameters such as rainfall, humidity, temperature, evapouration potential and wind speed which are critical. Such basic information would be useful in a wide range of ecological studies including factors regulating hippo population and climate change. With the purchase of weather equipment currently at ZAWA headquarters, it should be possible for South Luangwa Area Management Unit (SLAMU) to collect such data.

\section{v) Monitoring of Vegetation}

Hippo was found to be a dominant species among other herbivores along the alluvial belt of the Luangwa River. For that reason, hippo range requires research and monitoring in terms of structure and composition of vegetation in order to evaluate range condition and to determine impacts of high hippo population size on the range. Where possible, range improvement measures could be implemented when it is discovered that herbivore support capability of the range is deteriorating.

\section{vi) Research on Fire Ecology}

Fire is one of the major factors affecting vegetation change and loss of grass biomass in the dry season when it is needed most by hippos. Uncontrolled fires and increase in human settlements and associated farming activities in the dambos in the Lumimba and Lupande Game Management Areas in particular, would exacerbate food shortage for the hippo and should be managed through land use planning. Since habitat loss was one of the major factors identified to cause sudden declines in hippopotamus population in sub Sahara Africa [24], mitigating its impacts should be a priority. Additionally, current potential threats from global climatic change which may affect amount of rainfall received may have an impact on the amount of food produced and availability of water for cooling and wallowing. These factors including the impact of fire may have a negative impact on the hippo population and should be monitored.

vii) Detailed Soil Surveys in Relation to Fertility and Food Production (Grass Biomass)

Soil surveys are required to identify soil types present and to establish their relationship with spatial vegetation distribution and plant regeneration potential. This is critical in designing and implementing range management strategies to improve hippo pasture.

viii) Human Demography in Relation to Encroachment on Hippopotamus Habitat

Detailed studies on human population growth and distribution particularly in areas within $2-5 \mathrm{~km}$ of the river bank which is key hippo habitat should be monitored. Extensive loss of pasture within $2-5 \mathrm{~km}$ of river bank to human settlements would reduce the amount of food available to the hippo and would also increase humanhippo conflicts which often heightens negative attitudes towards hippo. Ultimately, this would increase the number of hippos killed under problem animal control.

\section{ix) Cooperation with Local Communities}

Management should reactivate and sustain community awareness programmes that promote cooperation with local communities in Game Management Areas, bordering South Luangwa National Park (SLNP) to protect lagoons and grasslands within $2-5 \mathrm{~km}$ of the river bank which is key hippo habitat. Loss of habitat due to human encroachment would reduce amount of food available to hippo and negatively impact on its population size.

\section{x) Law Enforcement}

Law enforcement surveillance and monitoring is very important in deterring poaching incursions. If poachers are not deterred the population may be locally exterminated or reduced to very low levels as the case was in the late 1800 and early 1900s when the species was almost locally extirpated.

\section{xi) Active Population Management}

The current population dynamics of population oscillations, leaves no doubt that it would require active management in order to maintain a healthy population. For as long as the population is maintained within the current Carrying Capacity Band, active management of the population will be required to keep the population in balance with its habitat. The non interference management option which is based on the concept of "cycle of over abundance followed by periods of low abundance" may not work with the hippo of the Luangwa Valley. In non interference theory, National Parks are thought to be natural ecosystems with regulatory feedback mechanisms which could restore the equilibrium [27]. However, examples are abound of a permanent drop in carrying capacity following a herbivore crash resulting from over use of the food resource [28]. Management should therefore, maintain active population management based on scientific data obtained from counts, habitat research and monitoring.

\section{xii) Translocation}

The Luangwa hippo population has reached carrying capacity $K$. For as long as the offtake remains within Carrying Capacity Band, the population size would not 
be negatively affected by the current levels of mortality. It could be advisable for ZAWA to consider several options including restocking new areas or supplementing small populations in other water bodies. However, translocation of hippo from one water body to another as a means of population regulation has been practiced on small scale. Massive capture and translocation of hippo still presents a practical challenge. Currently there are no practical methods for massive capture of hippo (Peter Mockle, personal comm.). Chemical mobilization is only possible when the animal is far from water. If darted near it or in water, the animal usually drowns while in anesthetic condition. Use of enclosures at a preferred grazing area as an alternative capture method, is a one-off activity as animals have to habituate first before they can be enclosed and captured. Culling, currently remains one of the most practicable medium to large scale population control strategy. It generates meat for the community and income for the management agency and the local community. Further research is required on better hippo capture methods and to improve the culling protocol so as to avoid disruption of social organization, age and sex structures, and to minimize complaints from the photographic tourism industry.

\section{b) Areas of Research Focus}

Given a background of inadequate research which has contributed to the paucity of ecological data, it is critical for ZAWA to initiate and maintain research and monitoring activities. The following areas of research have been suggested for inclusion in future research activities. It is also suggested that cost effective approaches such as making arrangements to tap into the skills of individuals and academic institutions including post graduate students from local and foreign universities should be considered. The following topics have been suggested.

\section{i) Hippopotamus Feeding Ecology}

The feeding style of the hippo influences structure and function of riparian habitats [29]. For instance, hippos feed on the flood plain and terrestrial grasses by night and return to water by day. Assuming each hippo consumes approximately $50 \mathrm{~kg}$ of grass daily as assumed in the present study and attested by other studies in South Africa [30] then each hippo would transfer approximately 3.2 metric tons of dry mass of faeces to the aquatic system annually [31]. In the Luangwa Valley, it is not uncommon to find hippo in water in densities exceeding 0.1 ha or higher which means that detritus (largely of terrestrial origin) in the amount of approximately 1 metric ton/ha is added to the water body annually [30]. In addition, because hippos are area selective bulk grazers, they reduce patches of tall grass to short grass thus enhancing contrast with the surrounding landscape patches. These examples imply that hippos influence habitat modification and requires detailed study to determine the impact on other species.

\section{ii) Influence of Hippopotamus Feeding on Other} Species

It is important to monitor population size of other herbivores in the area and where possible consider removing excessive numbers of one or more species that may have increased in response to the habitat changes induced by the primary over population. In Uganda for instance, an increase in species of herbivores that utilize tall grasslands was recorded when hippo was removed from Mweya Peninsula in Queen Elizabeth National Park, Uganda and Vice versa [32]. Secondary overpopulation would be an effect and not the primary cause of the problem and should be addressed only if the species involved continue to damage the ecosystem after the primary cause of the problem has been mitigated [32]. It would therefore, be logical to begin by reducing the species that the available evidence indicates is the one directly responsible for the overgrazing, but such decision requires scientific study.

\section{ACKNOWLEDGEMENTS}

We thank all the research assistants at Chinzombo Wildlife Research Centre for their dedication during hippo counts and the uniformed staff for protecting the survey team against dangerous animals. Mr. Chaka Kaumba ably prepared the location map of the area and we thank him for that. Several other people provided critique to the initial draft, their support is appreciated.

\section{REFERENCES}

[1] Tembo, A. (1987) Population status of the hippopotamus on the Luangwa River, Zambia. African Journal of Ecology, 25, 71-77.

http://dx.doi.org/10.1111/j.1365-2028.1987.tb01094.x

[2] Chansa, W., Senzota, R., Chabwela, H. and Nyirenda, V. (2011) The influence of grass biomass production on hippopotamus population density distribution along Luangwa River, Zambia. Journal of Ecology and the Natural Environment, 3, 186-194.

[3] Chomba, C., Senzota, R., Chabwela, H. and Nyirenda, V. (2012) Population status of the common hippopotamus (Hippopotamus amphibius) in Luangwa River, Zambia. Journal of Ecology and the Natural Environment, 4, 247 257.

[4] Chomba, C. (2013) Factors affecting the Luangwa (Zambia) hippo population dynamics within its carrying capacity band-Insights for better management. International Journal of Biodiversity and Conservation, 5, 109-121.

[5] Sinclair, A.R.E. and Grimsdell, J.J.R. (1982) Population dynamics of large mammals. African Wildlife Foundation, Nairobi.

[6] Chapman, J.L. and Reiss, M.J. (2000) Ecology, principles and application. Cambridge University Press, Cambridge.

[7] Mentis, M.T. and Duke, R.R. (1976) Carrying capacities 
of natural veld in natal for large wild herbivores. South African Journal of Wildlife Resources, 7, 65-74.

[8] Mentis, M.T. and Duke, R.R. (1976) Carrying capacity of natural veld in natal for large wild herbivores. South African Journal of Wildlife Research, 7, 89-98.

[9] Mentis, M.T. (1977) Stocking rates and carrying capacity for ungulates on African range lands. South African Journal of Wildlife Resources, 7, 89-98.

[10] Bell, R.H.V. (1986) Carrying capacity and off take quotas. In: Bell, R.H.V. and MacShane-Caluzi, E., Eds., Conservation and Wildlife Management in Africa, US Peace Corps., Washington DC.

[11] Chansa, W. and Milanzi, J. (2010) Population status of the hippopotamus in Zambia. African Journal of Ecology, 49, 130-132.

[12] Onyango, J.P. and Plews, A.M. (2005) A text book of basic statistics. East African Educational Publishers, Nairobi.

[13] Bothma, J.P. (2010) Game ranch management. J.L. van Schaik Publishers, Pretoria.

[14] Finerty, J.P. (1980) The population ecology of cycles of small mammals. Yale University Press, New Haven.

[15] Mduma, S.A.R., Sinclair, A.R.E. and Hilborn, R. (1999) Food regulates the Serengeti wildebeest: A 40-year record. Journal of Animal Ecology, 68, 1101-1122. http://dx.doi.org/10.1046/j.1365-2656.1999.00352.x

[16] Klein, D.R. and Olson, S.T. (1960) Natural mortality patterns of deer in southeastern Alaska. Journal of Wildlife Management, 24, 80-88. http://dx.doi.org/10.2307/3797359

[17] Klein, D.R. (1970) Food selection by North American deer and their response to over utilization of preferred plant species. Animal Populations in Relation to Their Food Resources, Blackwell, Oxford.

[18] Klein, D.R. (1972) Factors affecting growth and body size of roe deer. Journal of Wildlife Management, 36, 6479. http://dx.doi.org/10.2307/3799189

[19] Field, C.R. (1970) A study of the feeding habits of the hippopotamus in the Queen Elizabeth National Park, Uganda, with some management implications. African Zoology, 5, 71-86.

[20] Attwell, R.I.G. (1963) Surveying Luangwa hippo. Puku, 1,
$29-49$.

[21] Moffet, J.P. (1958) Handbook of Tanganyika. 2nd Edition, Government of Tanzania, Dar es Salaam.

[22] Smuts, G.L. and Whyte, I.J. (1981) Relationships between reproduction and environment in the hippopotamus in the Kruger National Park. Koedoe, 24, 169-185. http://dx.doi.org/10.4102/koedoe.v24i1.626

[23] Sayer, J.A. and Rhaka, A.M. (1974) The age of puberty in the hippopotamus (Hippopotamus amphibius) in the Luangwa River in eastern Zambia. East African Wildlife Journal, 12, 227-232.

[24] Lewison, R. (2007) Population responses to natural and human-mediated disturbances: Assessing the vulnerability of the common hippopotamus (Hippopotamus amphibius). African Journal of Ecology, 45, 407-415. http://dx.doi.org/10.1111/j.1365-2028.2006.00747.x

[25] Caughley, G. and Gunn, A. (1996) Conservation biology in theory and practice. Blackwell Science, Oxford.

[26] Caughley, G. (1977) Analysis of vertebrate populations. John Wiley and Sons, London.

[27] Barnes, R.F.W. (1983) The elephant problem in Ruaha National Park, Tanzania. Biology of Conservation, 26, $127-$ 148. http://dx.doi.org/10.1016/0006-3207(83)90062-9

[28] Noy-Meir, I. (1975) Stability of grazing systems: An application of the predator-Prey graphs. Journal of Ecology, 63, 459-481. http://dx.doi.org/10.2307/2258730

[29] Child, G. (1999) An evaluation of the hippopotamus impacts on habitats along the Luangwa River. A Report Submitted to the Norwegian Agency for International Development, Chipata.

[30] Owen-Smith, R.N. (1988) Megaherbivores: The influence of very large body size on ecology. Cambridge University Press, Cambridge. http://dx.doi.org/10.1017/CBO9780511565441

[31] Heeg, J. and Breen, C.M. (1982) Man and the Pongolo flood plain. Council for Scientific and Industrial Research, Report No. 56, Pretoria.

[32] Eltringham, S.K. (1974) Changes in the large mammal community of Mweya peninsula, Rwenzori National Park, Uganda, following removal of hippopotamus. Journal of Applied Ecology, 11, 855-865. http://dx.doi.org/10.2307/2401750 